\title{
Aplicação do Ciclo PDCA e Ferramentas da Qualidade na redução de Custos e Perdas em uma Distribuidora de Hortifruti
}

\author{
Rosane Sales de SOUSA \\ Centro Universitário Farias Brito (FBuni), Fortaleza, CE, Brasil \\ Maurício Johnny LOOS \\ Centro Universitário Farias Brito (FBuni), Fortaleza, CE, Brasil
}

\author{
Received 2 March 20; Accepted 9 July 20. \\ Evaluation System: Double Blind Review \\ Editor: Jose Lindenberg Julião Xavier Filho, Dr. \\ ISSN: $2594-8040$
}

To cite this paper: Souza, R. S., \& Loos, M. J. (2020). Aplicação do ciclo PDCA e ferramentas da qualidade na redução de custos e perdas em uma distribuidora de hortifruti. Journal of Perspectives in Management - JPM, 4, p. 68-83.

\section{Resumo}

As devoluções de produtos no ato da entrega ao cliente são responsáveis em grande parte pelo retrabalho e reprocesso, aumentando os custos da empresa e comprometendo a qualidade do produto final. Este trabalho tem como objetivo classificar e quantificar os motivos das devoluções, buscar causas, propor soluções e melhorias através da aplicação do ciclo PDCA e de ferramentas da qualidade, tais como: "Fluxograma", "Folha de Verificação", "Brainstorming", "Gráfico de Pareto", "Diagrama de Ishikawa" e " $5 \mathrm{~W} 2 \mathrm{H}$ ". O motivo mais frequente identificado foi o de devoluções por qualidade (49,9\%), seguido de acordo comercial $(20,8 \%)$ e excesso de mercadoria $(11,9 \%)$. As principais causas das devoluções por qualidade são devido ao recebimento de matériaprima de baixa qualidade e pela falta de inspeções de expedição dos produtos.

Palavras-Chave: Ferramentas da Qualidade; Devoluções; Hortifrúti. 


\section{Introdução}

O mundo está sempre em constante mudança e os consumidores estão cada vez mais exigentes. Diante disso, as empresas passam a ter necessidade de melhorar a eficiência de suas operações de forma cada vez mais rápida.

As frutas e hortaliças frescas possuem grande proporção de água em sua composição, o que motiva a grande perda de produtos, dificultando atender a demanda, pois o consumidor está cada vez mais exigente por qualidade. Atrelado a isso, as principais razões que contribuem para o desperdício de alimentos são: a falta de conhecimento técnico, falta de pessoal treinado e habilitado, o uso de práticas inadequadas e, principalmente, o desconhecimento de técnicas adequadas de manuseio pós-colheita (LEITE et al., 2019).

É nesse contexto que surge para as distribuidoras de hortifrúti a necessidade de realizar um planejamento estratégico, ou seja, algo que as coordene e dê uma direção. Para isso, deve-se definir onde se pretende chegar e o que deseja alcançar. É imprescindível o conhecimento da situação real pela qual a empresa encontra-se e, com base nessas informações, tentar traçar planos de ação em cima de oportunidades que apresentavam certa deficiência (ARAÚJO et al., 2016).

A gestão da qualidade apresenta-se como uma eficiente alternativa para dotar as empresas de mecanismos para controlar seus processos e melhorá-los continuamente de forma a atender e superar as expectativas do consumidor, promovendo, dessa forma, a melhoria organizacional e, consequentemente, o aumento da sua competitividade (OLIVEIRA et al., 2011).

Algumas ferramentas são essenciais para a boa execução da gestão da qualidade, dentre estas, tem-se: Ciclo PDCA, Fluxograma, Folha de Verificação, Gráfico de Pareto, Brainstorming, Diagrama de Ishikawa e 5W2H. Portanto, tem-se que é através da implementação de métodos de controle que os processos da empresa poderão ser monitorados e melhorados continuamente, refletindo nos resultados: externamente na qualidade de seus produtos e serviços, e internamente com menor índice de reprocesso, redução de custos e perdas, maximização do tempo de trabalho e melhor utilização dos espaços (DANIEL, 2014).

Com base no contexto apresentado, este trabalho tem como objetivo apresentar a utilização do ciclo PDCA e das ferramentas da qualidade em uma distribuidora de hortifrúti. O trabalho pretende responder à questão de como se pode reduzir custos e perdas com retrabalho e reprocesso garantindo a qualidade do produto final, através da utilização destas ferramentas.

O trabalho foi realizado em uma distribuidora de hortifrúti devido à necessidade desta em atender suas metas preestabelecidas e melhorar seus resultados. Para a coleta dos dados, foram utilizadas informações internas de indicadores e de análise de custos, as quais serão detalhadas mais à frente. Para cumprir seus objetivos, o trabalho primeiramente estabelece o referencial teórico, seguido pelos procedimentos metodológicos adotados, resultados e, finalmente, suas conclusões.

\section{Referencial Teórico}

A seguir é apresentada uma fundamentação teórica referente ao conceito de qualidade, ao Ciclo PDCA e às ferramentas da qualidade utilizadas no intuito de estabelecer a visão da literatura para, posteriormente, poder-se efetuar as análises de confronto no presente trabalho.

\subsection{Conceito de Qualidade}

Maiczuk (2013) menciona que a qualidade é um conjunto de atributos que tornam um serviço plenamente adequado ao uso. Esta satisfação envolve preço, disponibilidade, segurança e durabilidade. Define-se que qualidade é atender sempre as necessidades dos clientes a um preço que eles estejam dispostos a pagar, mas a necessidade da busca pela melhoria da qualidade tende a interpretar que a qualidade é produzir dentro das expectativas do cliente de forma confiável, acessível e segura. 


\subsection{Ciclo PDCA}

Segundo Souza (2016), o ciclo PDCA (Plan, Do, Check, Action) é uma ferramenta utilizada para obter melhorias na gestão de qualidade e em processos organizacionais. Para Falconi (2014), é uma metodologia para solução de oportunidades de melhoria, possibilitando que as diretrizes traçadas pelo planejamento estratégico sejam viabilizadas na empresa, sendo de extrema importância o engajamento de todos os colaboradores da organização com o método. Este ciclo é ininterrupto e visa a melhoria contínua, pois, usando o que foi aprendido em uma aplicação do ciclo PDCA, pode-se começar outro ciclo, em uma tentativa mais complexa e, assim, sucessivamente. Com isso, o último ponto sobre o ciclo PDCA se torna o mais importante, pois este assumirá um novo começo.

\subsubsection{Etapa do Ciclo PDCA}

De acordo com Souza (2016) o ciclo PDCA é organizado em quatro etapas, conforme podem ser notadas na Figura 1, e a explicação de cada etapa é dada a seguir:

P (PLAN - Planejar) - Situado no início do ciclo, esta etapa visa descrever as atividades e processos por meio de um cronograma de atividades e planejamento de metas, definições dos objetivos que uma organização pretende alcançar;

D (DO - Executar) - Na segunda etapa, a organização executa o planejamento realizado na primeira etapa, assim, torna-se fundamental o treinamento da equipe, e algumas modificações culturais na empresa. Nesta fase, deve-se implantar os processos e atividades planejadas;

C (CHECK - Checar) - A terceira fase do ciclo é basicamente a verificação das ações, a análise do que foi planejado e o que foi realmente executado. A comparação será sempre realizada por meio de políticas e objetivos dos clientes; e

A (ACTION - Agir) - Na última etapa, se forem identificados erros, é necessário programar soluções que alterem as suas causas; caso não identifiquem erros, é possível reconhecer futuros desvios e realizar um trabalho preventivo para uma melhoria contínua.

Figura 1: Representação do Ciclo PDCA

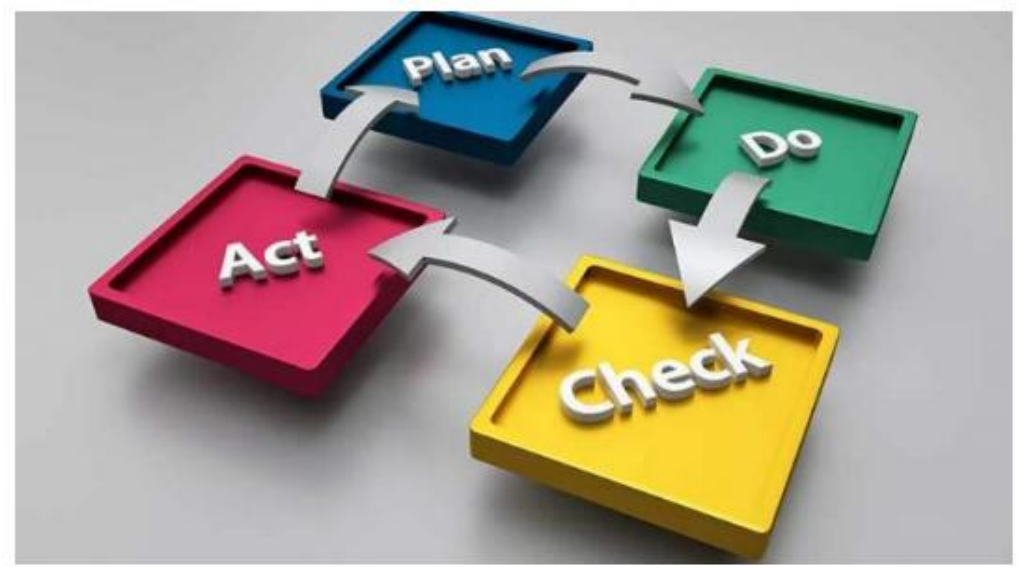

Fonte: Bertolino (2019)

\subsection{Ferramentas da Qualidade}

As ferramentas da qualidade são métodos utilizados para a melhoria de processos e solução de problemas em qualidade. $\mathrm{O}$ uso dessas ferramentas tem como objetivo a clareza no trabalho e principalmente a tomada de decisão com base em fatos e dados, ao invés de opiniões. As 
ferramentas são utilizadas na indústria por ter a grande capacidade em remover as causas dos problemas, onde se obtém uma maior produtividade e a redução de perdas (MAICZUK, 2013).

Na primeira etapa do ciclo PDCA (planejar) é onde é possível identificar o problema a ser trabalhado e onde se define como chegar à solução. Nessa etapa é que se faz uso de diversas ferramentas da qualidade a fim de identificar e analisar o problema. Dentre essas ferramentas, podese citar as utilizadas neste trabalho: Fluxograma, Folha de Verificação, Gráfico de Pareto, Brainstorming, Diagrama de Ishikawa e 5W2H. Segundo Araújo (2012), a utilização de ferramentas da qualidade atreladas ao conhecimento e sensatez dos gestores, auxiliam no atendimento das expectativas da organização em alcançar melhores resultados.

\subsubsection{Fluxograma}

De acordo com Souza et al. (2016), o fluxograma é uma ferramenta que mostra de forma gráfica as etapas de um processo. Pode ser utilizado na análise de um processo corrente, pois permite a compreensão rápida do fluxo de atividades. A utilização desta ferramenta ajuda a identificar possíveis causas dos problemas que ocorrem nas linhas de processo de fabricação, eliminando os passos desnecessários no processo, efetuando simplificações.

\subsubsection{Folha de Verificação}

Com base em Souza (2016), folhas de verificação são tabelas ou planilhas usadas para facilitar a coleta de dados num formato sistemático para compilação e análise. Seu uso permite poupar tempo, pois elimina o trabalho de se desenharem figuras ou escrever números repetitivos, evitando comprometer a análise dos dados. Serve para a observação de fenômenos, permitindo uma visualização da existência dos diversos fatores envolvidos e seus padrões de comportamento.

Dentre os diversos tipos de listas de verificação, a ideia básica é sempre a mesma: agrupar os fatos em classes, cada qual adaptada para as finalidades a que se destinam. Porém, para ser usada com eficácia, é importante ter-se compreensão clara do objetivo da coleta de dados e dos resultados finais que dela podem se originar.

\subsubsection{Gráfico de Pareto}

Coletti et al. (2010) definem o Gráfico de Pareto como uma técnica para registrar e analisar informações que permitem a priorização da tomada de decisão. A utilização desse gráfico é muito interessante porque sugere em quais erros ou atividades devem ser concentradas prioritariamente as ações de melhoria.

\subsubsection{Brainstorming}

Brainstorming é uma técnica de criatividade em grupo, a qual busca a geração de ideias que, isoladamente ou associadas, estimulem novas ideias e subsídios direcionados à solução parcial ou total de um problema. De acordo com Behr et al. (2008), o brainstorming deve priorizar a quantidade e não a qualidade das ideias e pode ser conduzido de duas maneiras. Uma estrutura, na qual são feitas rodadas e cada participante deve dar uma ideia ou dizer "passo" ao chegar a sua vez, assim quando só restar um participante dando ideias, encerra-se a técnica; e outra forma nãoestruturada, na qual o grupo se reúne e livremente expõe suas ideias. 


\subsubsection{Diagrama de Ishikawa}

O Diagrama de Ishikawa, também conhecido como Diagrama de Causa e Efeito ou Espinha de Peixe, é uma das sete ferramentas mais tradicionais da qualidade e tem como objetivo representar fatores de influência (causas) sobre um determinado problema (efeito), como pode ser visto na Figura 2 (DE AZEVEDO et al., 2014). Assim, sua aplicação é ampla e oferece suporte para as decisões relativas a situações que devem ser mantidas ou eliminadas.

De Azevedo et al. (2014) explana que esta ferramenta consiste em uma forma gráfica usada como metodologia de análise e que pode ser elaborada seguindo os seguintes passos:

- Determinar o problema;

- Relatar sobre as possíveis causas;

- Construir o diagrama agrupando as causas em "6Ms" (Método, Matéria-prima, Mão-de-obra, Máquinas, Materiais, Meio Ambiente);

- Analisar o diagrama, a fim de identificar as causas verdadeiras;

- Corrigir o problema.

Figura 2: Representação do Diagrama de Ishikawa

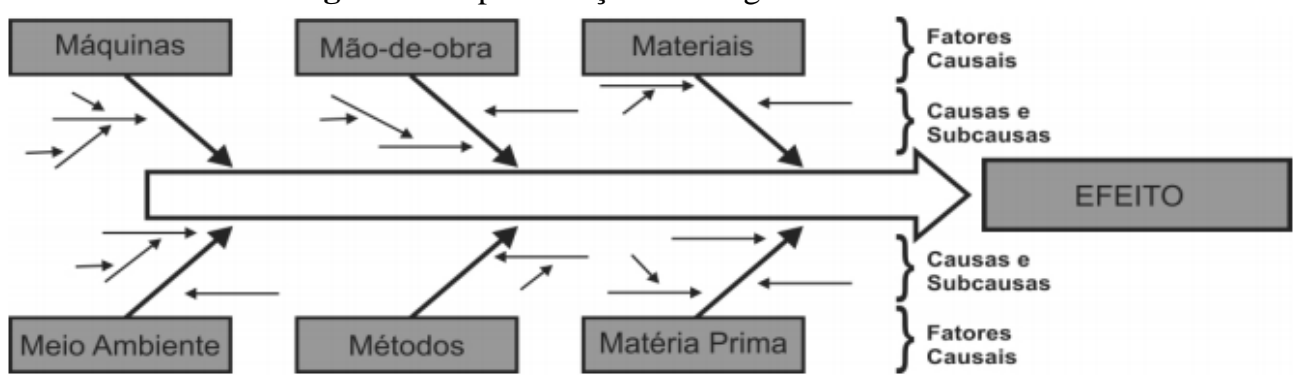

Fonte: De Azevedo et al., (2014)

\subsubsection{W2H (Plano de Ação)}

Após a identificação do problema, apresentação de sua evolução e levantamento de todos os dados já se conhece a causa raiz do problema que deve ser tratado. Com isso, é mais fácil desenhar um plano para sua tratativa. Assim, pode-se passar para a última ferramenta: $5 \mathrm{~W} 2 \mathrm{H}$ ou plano de ação (MORAIS e LOOS, 2016).

Para utilizar-se o 5W2H deve-se fazer o uso das seguintes perguntas: What: qual ação será desenvolvida (etapas); Why: qual será o resultado esperado da ação (justificativa); Where: onde a ação será desenvolvida (local); When: quando será realizada (tempo); Who: por quem será feita (responsabilidade); How: como será feita (método); How much: quanto custará para fazer (custo).

Ou seja, para elucidar uma oportunidade de melhoria, esta ferramenta auxilia na elaboração de um plano de ação através das respostas organizadas das sete questões básicas, além de ajudar também a melhorar a segregação de tarefas dentro de um processo e a ver, de maneira gerencial, como os processos estão se desenvolvendo.

\section{Procedimentos Metodológicos}

O ciclo PDCA e as ferramentas da qualidade possuem formas de organização e aprofundamento que facilitam bastante as análises e os alinhamentos de ações necessárias (MORAIS e LOOS, 2016). O presente trabalho tem como propósito apresentar a utilização do ciclo PDCA e das ferramentas da qualidade em uma distribuidora de hortifrúti, demonstrando como pode-se reduzir custos e perdas com retrabalho e reprocesso, garantindo a qualidade do produto final. 
Nesse contexto, este trabalho utiliza como abordagem metodológica o estudo de caso, o qual trata-se de uma investigação especialmente adequada quando procura-se compreender, explorar ou descrever acontecimentos e contextos complexos, nos quais estão simultaneamente envolvidos diversos fatores (MORAIS e LOOS, 2016).

A seleção do objeto de análise (empresa) ocorreu devido à necessidade da mesma em atender suas metas preestabelecidas e melhorar seus resultados. Este trabalho foi baseado nos dados de uma empresa fundada há 22 anos, que comercializa e distribui frutas, verduras e legumes, com matriz situada na Paraíba e mais quatro Centros de Distribuição (CDs) localizados em cidades estratégicas do Nordeste.

\subsection{Coleta de Dados}

Os dados utilizados neste trabalho são da unidade localizada em Maracanaú - Ceará, no período de janeiro a agosto de 2019, de acordo com os passos apresentados na Figura 3 para se atingir o objetivo apresentado. A forma como as ferramentas foram aplicadas está descrita na próxima seção.

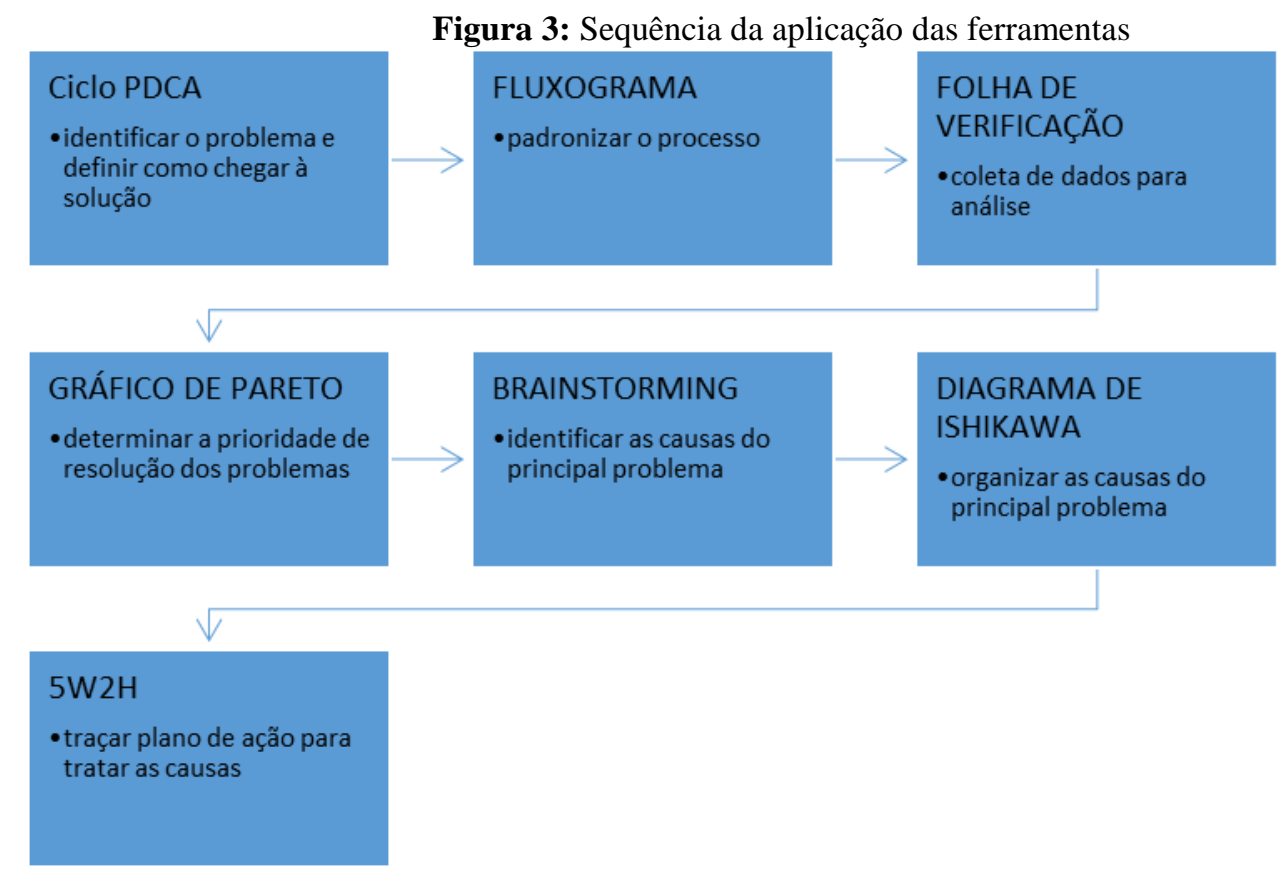

Fonte: Elaborado pela autora (2020)

Assim, o ciclo PDCA foi aplicado inicialmente para identificar o problema e definir como chegar às soluções. Em seguida, o Fluxograma foi elaborado para facilitar a eliminação dos passos desnecessários do processo, simplificando-o e padronizando-o. A Folha de Verificação permitiu a análise dos dados e validação da causa real. Após o problema identificado e quantificado, o Brainstorming foi aplicado para identificar as causas do principal problema. O Diagrama de Ishikawa serviu como um organizador visual para facilitar o entendimento das causas e efeitos e possíveis focos das causas que geravam o problema. E, por fim, a ferramenta $5 \mathrm{~W} 2 \mathrm{H}$ tornou claro o plano de ação traçado para solucionar o problema. 


\section{Discussões dos Resultados}

A distribuidora de hortifrúti estudada é uma empresa que comercializa e distribui frutas, verduras e legumes in natura e que vem passando por um processo de adaptação devido à necessidade em atender suas metas e melhorar seus resultados, pois embora o faturamento da empresa aumente gradativamente com o passar dos meses, os valores de perdas (mercadorias avariadas) e de devoluções (recusas de produtos no ato da entrega ao cliente) também evolui substancialmente.

Um dos maiores custos da empresa acontece no processo de devolução de mercadorias e este provoca, consequentemente, o aumento dos valores de perda, tendo em vista que uma carga completa ou produto devolvido perde qualidade durante seu retorno à empresa, tornando-se, em sua maioria, impróprio à venda.

\subsection{Ciclo PDCA}

Inicialmente, aplicou-se o Ciclo PDCA ilustrado na Figura 4 para o indicador Devoluções, cujo cálculo será demonstrado logo a seguir:

Figura 4: Ciclo PDCA para o Indicador Devoluções/ mês Janeiro

INDICADOR: DEVOLUÇÕES

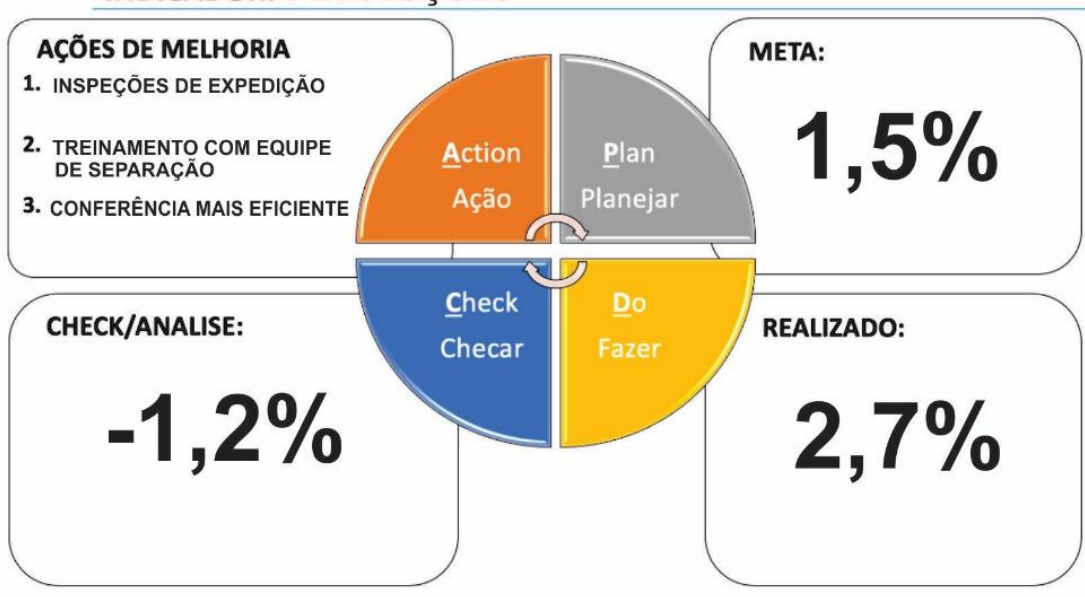

Fonte: Elaborado pela autora (2019)

Indicador Devoluções: é a relação entre o valor acumulado de devoluções, em reais, e o valor acumulado de vendas, em reais, para toda a Unidade, em determinado período.

\section{Devoluções $=\sum$ Devoluções $(R \$) / \sum$ Vendas $(R \$)$}

Por meio da Figura 4, pode-se observar que a meta do indicador de devoluções da empresa de estudo é $1,5 \%$. Utilizou-se como referência o mês de janeiro, o qual obteve como resultado $2,7 \%$ e, portanto, o não atingimento da meta preestabelecida. Com base nos motivos de devoluções já conhecidos pela empresa, que são: avaria, qualidade, excesso de mercadoria, falta de mercadoria, atraso na entrega, diferença de preço, erro de digitação do vendedor, desacordo com o pedido, falha operacional e acordo comercial, foram listadas três ações de melhoria como possíveis soluções para o problema de devoluções, sendo elas:

- Treinamento com a equipe de separação de pedidos com a finalidade de reduzir quaisquer divergências com o que foi solicitado pelo cliente. Neste treinamento foram abordados os padrões de exigência de cada cliente, com base nas fichas técnicas dos mesmos e os principais defeitos dos produtos com baixo shelf life e com maior frequência de apresentarem problemas pós colheita, explanando com imagens para que a fixação do conteúdo fosse mais efetiva pelos funcionários; 
- Inspeções de expedição como forma de identificar algum desvio com relação ao padrão do produto selecionado. Estas inspeções foram realizadas através de relatórios nos quais eram registrados: temperatura, validade, integridade da embalagem, peso líquido, calibre, paletização, presença de danos, firmeza e maturação do produto já separado para a expedição.

- Conferência mais eficiente para evitar problemas de falta ou excesso de mercadoria. O pedido, após separado, passou a ser conferido "às cegas" e reconferido com nota físcal.

\subsection{Fluxograma}

Após o problema identificado e a forma como chegar às soluções definidas, o segundo passo foi elaborar o Fluxograma "Devoluções de Clientes" (Figura 5) que foi utilizado para padronização do processo de retorno da mercadoria devolvida. Conforme mostra o fluxograma, o processo se inicia com a chegada do veículo trazendo a devolução do cliente na empresa. $\mathrm{Na}$ sequência, o motorista deve apresentar a nota fiscal de devolução ao encarregado de recebimento e este deve conferir se todos os produtos devolvidos acompanham a nota fiscal. Após conferência, os produtos devem ser descarregados pela equipe de descarrego e o pallet deve ser identificado. $\mathrm{O}$ encarregado de recebimento deve então preencher o formulário "Controle de Recebimento de Devoluções" no qual consta a lista de motivos de devoluções. Após a armazenagem do pallet no local adequado, o Controle de Qualidade deve ser acionado para inspecionar a mercadoria devolvida e direcioná-la para o descarte, repasse ou estoque. Em seguida, o auxiliar logístico deve realizar no sistema a entrada da nota fiscal de devolução de acordo com os apontamentos de perdas registrados pelo Controle de Qualidade. 

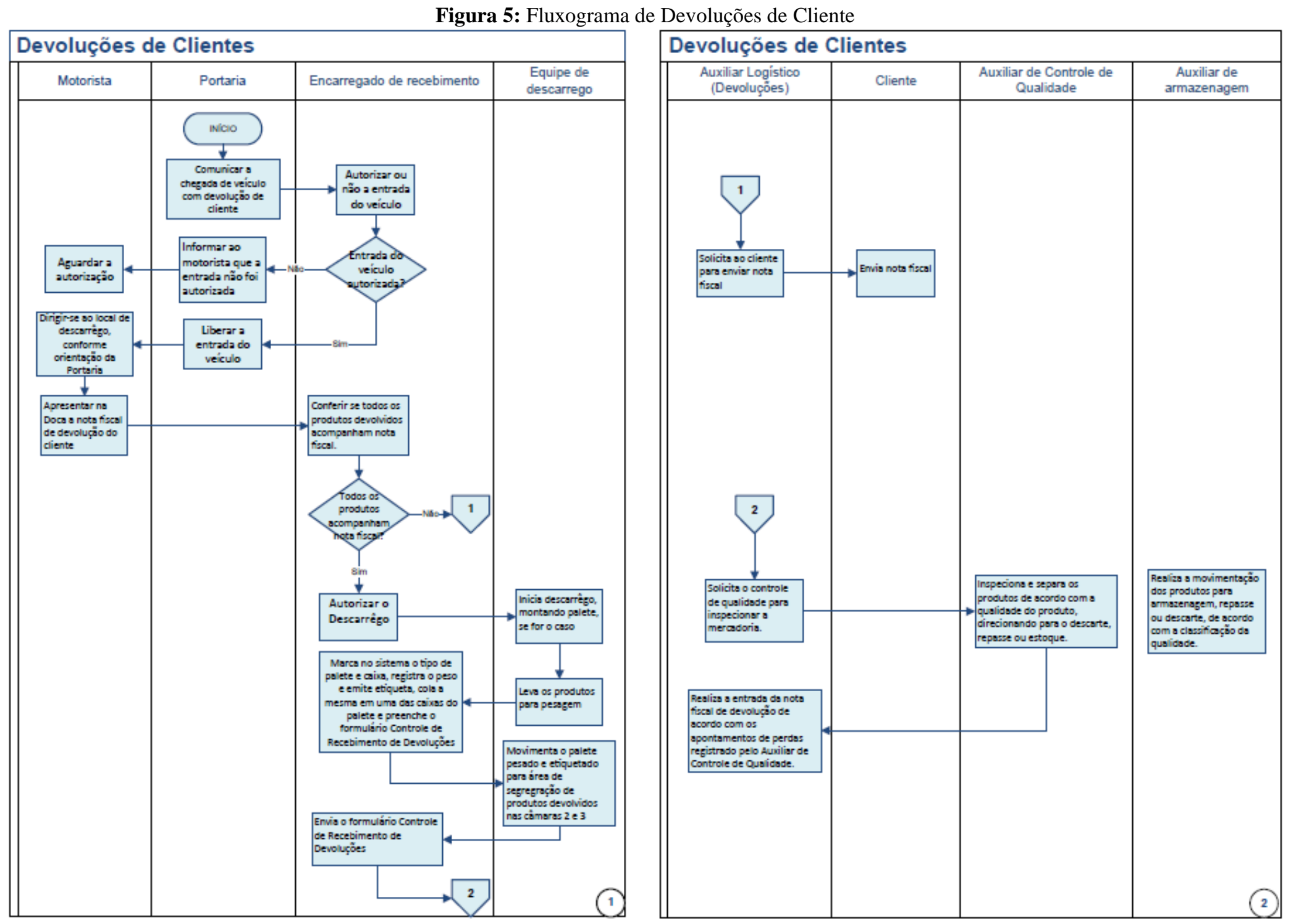

Fonte: Elaborado pelo setor logístico da empresa de estudo (2019) 


\subsection{Folha de Verificação}

O formulário Controle de Devoluções (Figura 6) preenchido pelo encarregado de recebimento com o motivo da devolução recebida foi utilizado como Folha de Verificação com a finalidade de coletar os dados e iniciar o levantamento das causas mais frequentes das devoluções.

Figura 6: Formulário Controle de Recebimento de Devoluções

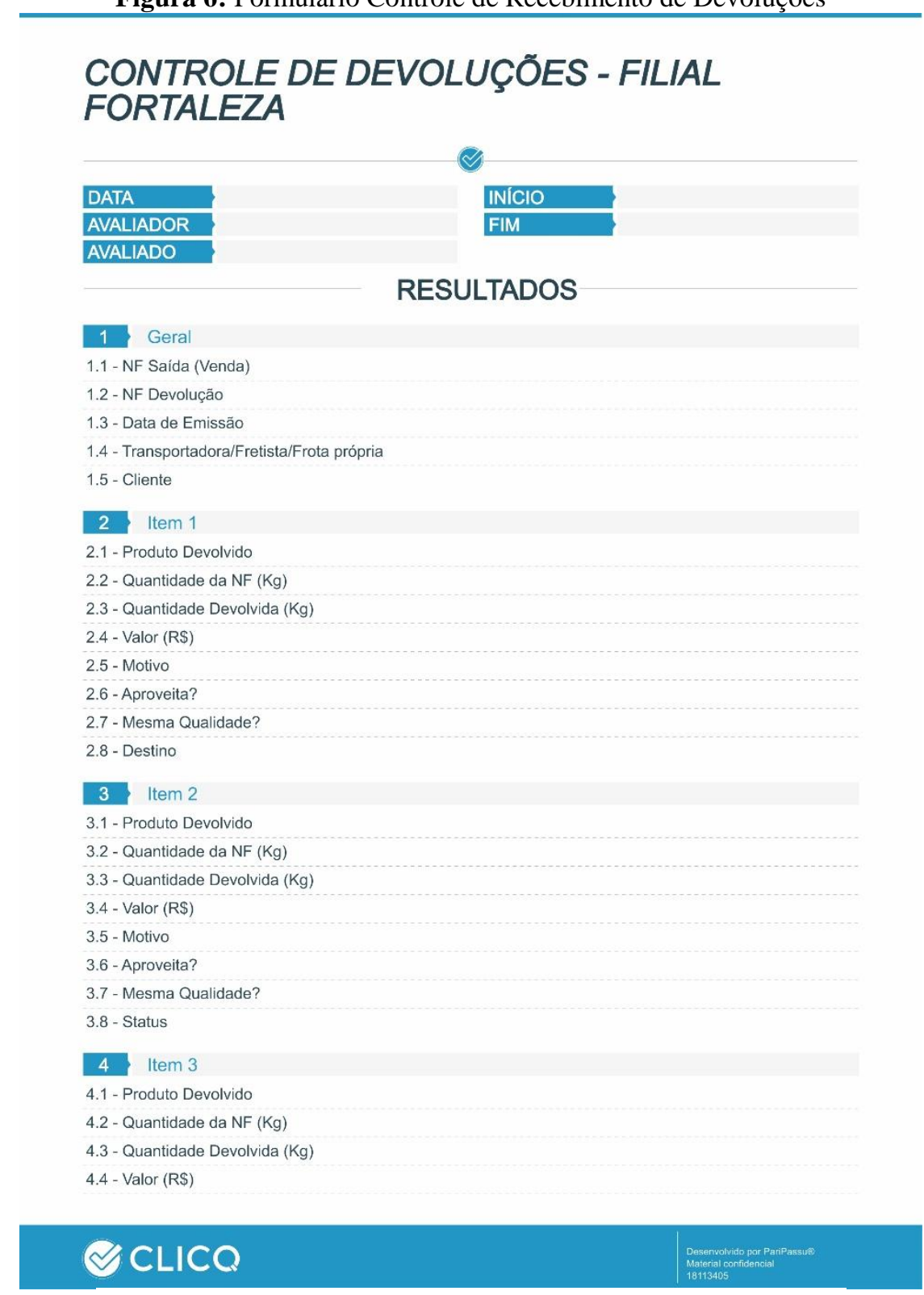

Fonte: Elaborado pelo setor logístico da empresa de estudo (2019)

A Tabela 1 a seguir foi elaborada para demonstrar os dados coletados através da Folha de Verificação, cujo mês de referência utilizado foi janeiro. 
Tabela 1: Folha de Verificação/ janeiro

\begin{tabular}{lcc}
\hline \multicolumn{1}{c}{ Motivos das devoluções } & \% & \% acumulado \\
\hline Qualidade & $49,9 \%$ & $49,9 \%$ \\
Acordo comercial & $20,8 \%$ & $70,7 \%$ \\
Excesso de mercadoria & $11,9 \%$ & $82,6 \%$ \\
Falta de mercadoria & $7,7 \%$ & $90,3 \%$ \\
Diferença de preço & $6,6 \%$ & $96,9 \%$ \\
Desacordo com o pedido & $2,0 \%$ & $98,9 \%$ \\
Avaria & $1,1 \%$ & $100,0 \%$ \\
\hline
\end{tabular}

Fonte: Elaborado pela autora (2019)

De acordo com a Tabela 1 pode-se observar que a maior porcentagem de motivos das devoluções foi por padrão de qualidade, correspondendo a 49,9\% do total. Neste motivo estão incluídos os seguintes parâmetros: podridão, presença de danos, divergência de calibre, data crítica/ produto vencido, baixa firmeza, maturação avançada/ atrasada, dentre outras características que comprometam a qualidade e integridade física do produto.

Na sequência, foram obtidos por ordem decrescente de frequência os seguintes motivos das devoluções: acordo comercial, excesso de mercadoria, falta de mercadoria, diferença de preço, desacordo com o pedido e avaria.

\subsection{Diagrama de Pareto}

Figura 7: Gráfico de Pareto para os principais motivos de devoluções

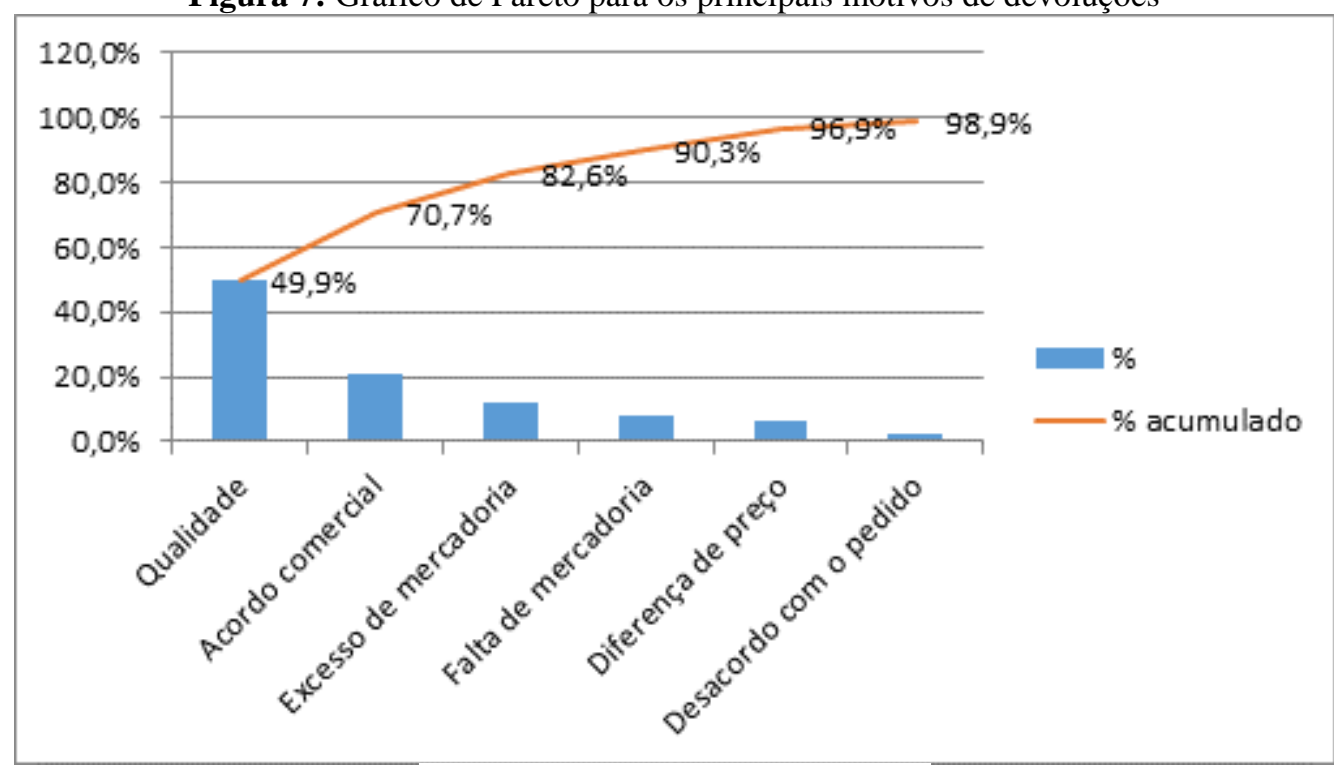

Fonte: Elaborado pela autora (2019)

Coletti et al. (2010) mencionam que somente $20 \%$ das causas são responsáveis por $80 \%$ dos problemas nas organizações. Nesse caso, como pode-se observar na Figura 7, tem-se que padrão de qualidade, acordo comercial e excesso de mercadoria são responsáveis por $82,6 \%$ dos motivos das devoluções e deverão ser o foco das ações corretivas e/ou preventivas. 


\subsection{Brainstorming}

Após a fase de identificação e quantificação dos principais motivos das devoluções, foi realizado um Brainstorming para indicação das possíveis causas. O Brainstorming foi realizado em conjunto com todas as pessoas envolvidas (líderes dos setores de administração, comercial, qualidade, recebimento, expedição e gerência), no qual cada um teve espaço para falar uma possível causa para o principal problema de devoluções de mercadorias no ato da entrega ao cliente: Qualidade. Desta maneira, obteve-se como possíveis causas: compra e recebimento de matériaprima de baixa qualidade, baixo giro de estoque ocasionando produto com data crítica ou vencido, embalagem avariada, condições de temperatura de transporte não conforme, instabilidade nas condições da temperatura de armazenamento, ausência de inspeção de qualidade na expedição, falta de conhecimento sobre padrão de cada cliente pelos funcionários do repasse e separação de pedidos.

\subsection{Diagrama de Ishikawa}

Na Figura 8 encontra-se a aplicação do Diagrama de Ishikawa para o principal motivo das devoluções que é a qualidade do produto, através das ideias apresentadas no Brainstorming. Nota-se que nem todas as categorias foram utilizadas devido ao grau de complexidade do problema.

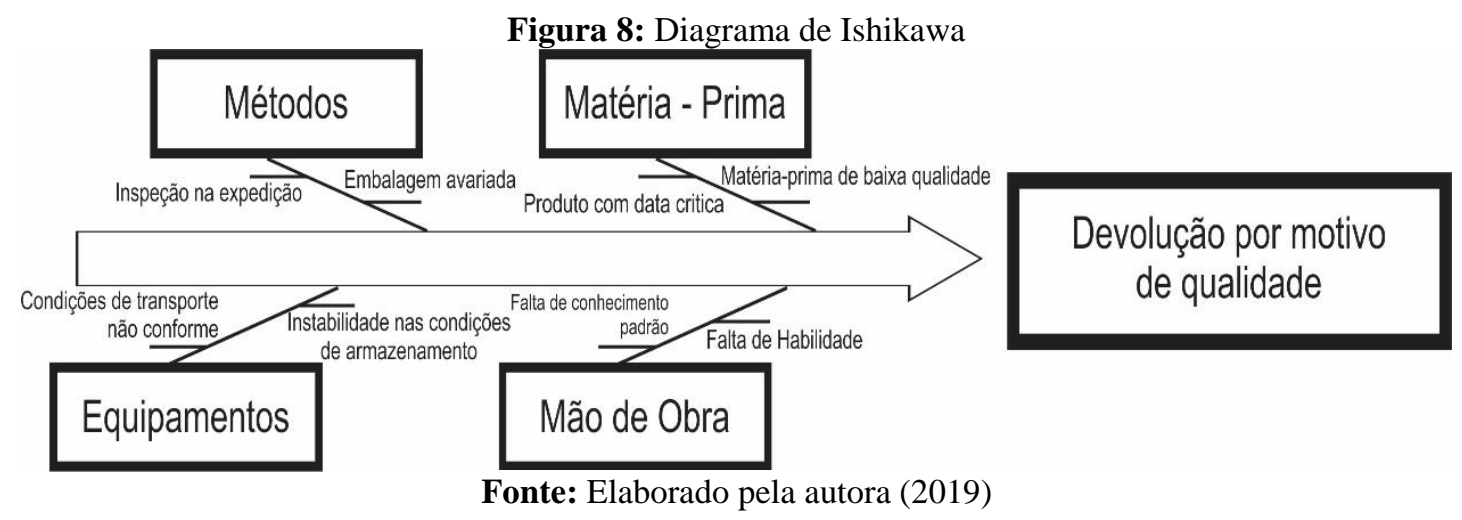

O resultado da busca de causas pelo Diagrama de Ishikawa confirma que as devoluções por motivo de qualidade são, principalmente, provenientes da compra e recebimento de matérias-primas de baixa qualidade e devido ao baixo giro de estoque, pois, se referindo a produtos in natura e, em sua maioria, de baixo shelf life, esses dois pontos são cruciais na determinação da vida de prateleira do produto.

A utilização desta ferramenta permitiu verificar também que há necessidade de frequentes manutenções preventivas nos equipamentos das câmaras frias, além da correta escolha dos transportes para a manutenção da cadeia de frio.

\subsection{Plano de Ação (5W2H)}

A Tabela 2 representa graficamente o Plano de Ação "5W2H" para o problema de devolução por motivo de qualidade, porém neste caso não está apresentado o $H O W M U C H$ (quanto custa) por se tratar de uma informação confidencial. 
Tabela 2: Plano de ação para devoluções por motivo de qualidade

\begin{tabular}{|c|c|c|c|c|c|}
\hline $\begin{array}{l}\text { O que fazer } \\
\text { (What) }\end{array}$ & $\begin{array}{c}\text { Onde } \\
\text { (where) }\end{array}$ & Por quê (Why) & $\begin{array}{l}\text { Quando } \\
\text { (When) }\end{array}$ & $\begin{array}{l}\text { Quem } \\
\text { (Who) }\end{array}$ & Como (How) \\
\hline $\begin{array}{l}\text { Inspeção de } \\
\text { recebimento } \\
\text { mais rigorosa }\end{array}$ & $\begin{array}{c}\text { Setor de } \\
\text { recebimento } \\
\text { de matéria- } \\
\text { prima }\end{array}$ & $\begin{array}{c}\text { Evitar recebimento de } \\
\text { matéria-prima de baixa } \\
\text { qualidade }\end{array}$ & $\begin{array}{l}\text { Toda vez que } \\
\text { receber carga de } \\
\text { fornecedor }\end{array}$ & $\begin{array}{l}\text { Equipe do } \\
\text { Controle de } \\
\text { Qualidade }\end{array}$ & $\begin{array}{l}\text { Relatórios de } \\
\text { inspeção }\end{array}$ \\
\hline $\begin{array}{l}\text { Inspeção de } \\
\text { expedição mais } \\
\text { rigorosa }\end{array}$ & $\begin{array}{l}\text { Setor de } \\
\text { expedição de } \\
\text { pedidos }\end{array}$ & $\begin{array}{c}\text { Evitar a expedição de } \\
\text { produtos com problema } \\
\text { de qualidade }\end{array}$ & $\begin{array}{l}\text { Toda vez que } \\
\text { for expedir um } \\
\text { pedido }\end{array}$ & $\begin{array}{l}\text { Equipe do } \\
\text { Controle de } \\
\text { Qualidade }\end{array}$ & $\begin{array}{l}\text { Relatórios de } \\
\text { inspeção }\end{array}$ \\
\hline $\begin{array}{l}\text { Treinamento } \\
\text { com a equipe de } \\
\text { separação de } \\
\text { pedidos }\end{array}$ & $\mathrm{Na}$ empresa & $\begin{array}{c}\text { Promover um } \\
\text { conhecimento mais } \\
\text { aprofundado sobre a } \\
\text { peculiaridade de cada } \\
\text { cliente }\end{array}$ & $\begin{array}{c}\text { A cada } 3 \text { meses } \\
\text { ou sempre que } \\
\text { necessário }\end{array}$ & $\begin{array}{l}\text { Equipe do } \\
\text { Controle de } \\
\text { Qualidade }\end{array}$ & $\begin{array}{l}\text { Através de } \\
\text { vídeos e } \\
\text { exposição } \\
\text { visual }\end{array}$ \\
\hline $\begin{array}{l}\text { Manutenção } \\
\text { preventiva } \\
\text { câmaras frias }\end{array}$ & Câmaras frias & $\begin{array}{l}\text { Evitar oscilação na } \\
\text { temperatura de } \\
\text { armazenamento }\end{array}$ & $\begin{array}{l}\text { Mensalmente ou } \\
\text { sempre que } \\
\text { necessário }\end{array}$ & $\begin{array}{l}\text { Equipe de } \\
\text { manutenção }\end{array}$ & $\begin{array}{l}\text { Limpeza e } \\
\text { ajuste dos } \\
\text { evaporadores }\end{array}$ \\
\hline
\end{tabular}

Fonte: Elaborado pela autora (2019)

Com base no estudo realizado e utilização das ferramentas da qualidade, para redução de custos e perdas pode-se observar que as Devoluções por motivo geral (Figura 9) e Devoluções por motivo de qualidade (Figura 10) diminuíram no decorrer do período de janeiro a agosto.

Figura 9: Gráfico de Devoluções por motivo geral 2018 x 2019

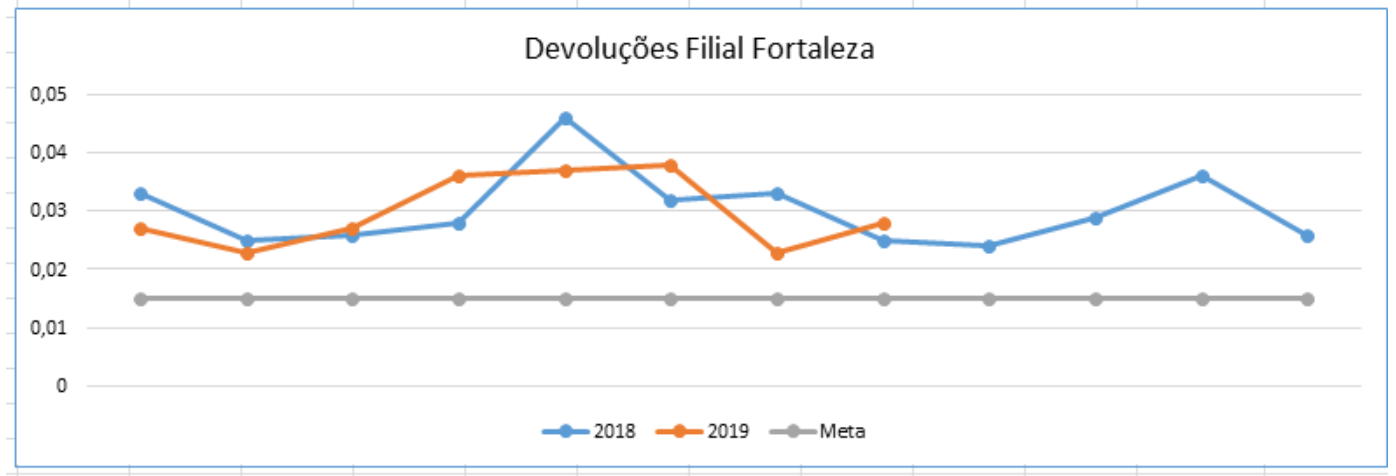

Fonte: Elaborado pela autora (2019)

Figura 10: Gráfico de Devoluções por motivo de qualidade 2018 x 2019

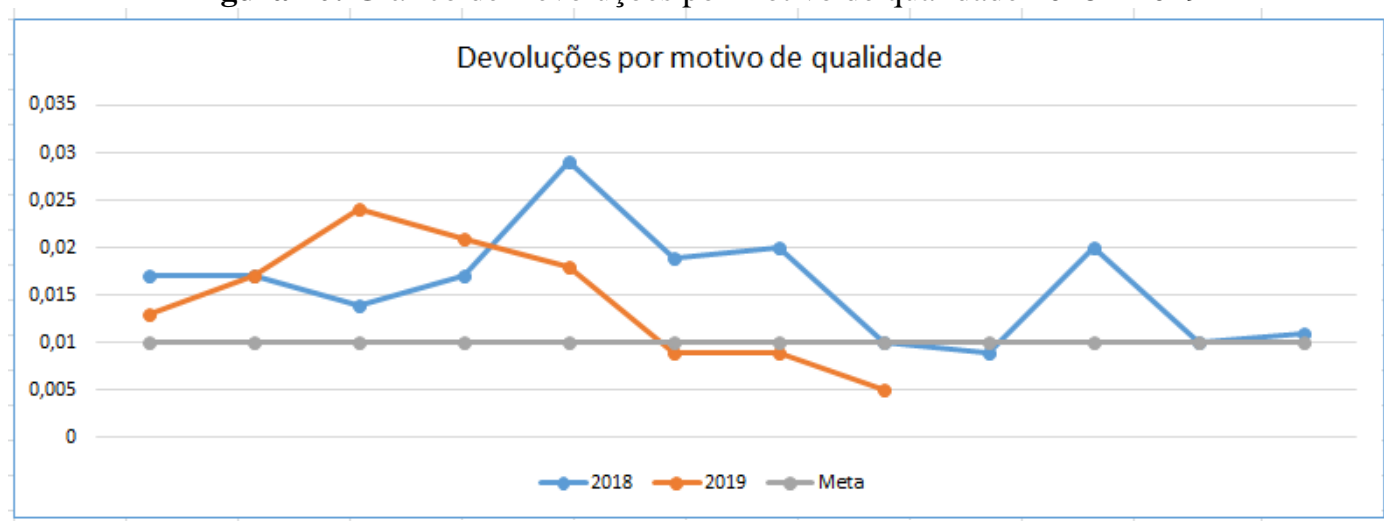

Fonte: Elaborado pela autora (2019) 


\section{Conclusões}

Baseando-se nos estudos realizados neste trabalho, as seguintes conclusões podem ser apresentadas:

- O motivo mais frequente encontrado no processo de devoluções foi por Qualidade, que engloba uma série de parâmetros que determina o padrão de qualidade e integridade física do produto e que deve ser avaliada em conjunto, pois um impacta diretamente no resultado do outro;

- A principal causa para a ocorrência das devoluções por qualidade é a compra e o recebimento de matéria-prima com qualidade comprometida e o baixo giro de estoque da mesma. A realização de inspeções de recebimento e de expedição mais rigorosas, assim como a agilidade na venda negociada com o cliente do produto com baixo shelf life solucionaram o principal problema;

- O plano de ação proposto neste trabalho reduziu o percentual de devoluções por motivo de qualidade e perdas consequentes do anterior, com a melhoria do processo e uma equipe mais motivada e com nível de conhecimento mais elevado.

Para a realização de trabalhos futuros sugere-se que a variável custo seja mais utilizada, visto que desta forma os impactos das melhorias possam ficar ainda mais evidentes.

\section{Referências}

Aguiar, S. (2012). Integração das ferramentas da qualidade ao PDCA e ao programa Seis Sigma. Nova Lima: INDG.

Araújo, L. C. D. (2012). Organização, sistemas e métodos e as tecnologias de gestão organizacional. 4. ed. São Paulo: Atlas.

Araújo, M. G., Queiroz, J. V., Lima, J. C. F., De Medeiros Fernandes, G., Queiroz, F. C. B. P., \& Furukava, M. (2016). Aplicação do ciclo PDCA na elaboração de um plano estratégico e implementação da Curva ABC como ferramenta de suporte para o gerenciamento de estoques de uma distribuidora de alimentos hospitalares. Revista ESPACIOS, 37(13).

Behr, A., Moro, E. L. D. S., \& Estabel, L. B. (2008). Gestão da biblioteca escolar: metodologias, enfoques e aplicação de ferramentas de gestão e serviços de biblioteca. Ciência da informação,. 37(2), maio/ago.

Coletti, J., Bonduelle, G. M., \& Iwakiri, S. (2010). Avaliação de defeitos no processo de fabricação de lamelas para pisos de madeira engenheirados com uso de ferramentas de controle de qualidade. Acta Amazônica, 40(1), 135-140.

Daniel, É. A., \& Murback, F. G. R. (2014). Levantamento bibliográfico do uso das ferramentas da qualidade. Revista Gestão \& Conhecimento, 8, 1-43.

De Azevedo F. M., De Oliveira, U. R., \& De Almda Garcia, P. A. (2014). Quatro ferramentas administrativas integradas para o mapeamento de falhas: um estudo de caso. Revista Uniabeu, 7(16), 300-315.

Falconi, V. (2014) TQC: controle da qualidade total (no estilo japonês). 8. ed. Nova Lima, MG: INDG Tecnologia e Serviços Ltda.

Junior, C. C. M. F. (2010). Aplicação da Ferramenta da Qualidade (Diagrama de Ishikawa) e do PDCA no Desenvolvimento de Pesquisa para a reutilização dos Resíduos Sólidos de Coco Verde. Revista Gestão e Produção, 2(9), 104-112.

Leite, J. F., Zuninga, A. D. G., Feitosa, A. C., \& Barbosa, M. C. (2019). Avaliação das condições de armazenamento dos alimentos na central de abastecimento (CEASA) de Palmas-TO. DESAFIOS - Revista Interdisciplinar Da Universidade Federal Do Tocantins, 6(1), 15-22.

Maiczuk, J., \& Júnior, P. P. A. (2013). Aplicação de ferramentas de melhoria de qualidade e produtividade nos processos produtivos: um estudo de caso. Qualitas Revista Eletrônica, 14(1). 
Morais, L. C., Loos, M. J. (2016). A utilização do ciclo PCDA para análise de indicadores de desempenho logístico em uma empresa do ramo alimentício. Revista FFBusiness, 185-208.

Oliveira, J. A., de Nadae, J., De Oliveira, O. J., \& Salgado, M. H. (2011). Um estudo sobre a utilização de sistemas, programas e ferramentas da qualidade em empresas do interior de São Paulo. Production, 21(4), 708-723.

Polacinski, E., et al. (2012). Implantação dos 5Ss e proposição de um SGQ para uma indústria de erva-mate. Gestão Estratégica: Empreendedorismo e Sustentabilidade - Congresso Internacional de Administração.

Souza, C. F. P., Da Silva, A. M., \& Maniçoba, R. F. (2016). Aplicação das ferramentas da qualidade: estudo de caso em pequena empresa de pintura. Refas-Revista Fatec Zona Sul, 3(1), $31-45$.

Souza, J. M. (2016). PDCA e Lean Manufacturing: Estudo de caso de aplicação de processos de qualidade na Gráfica Alfa. Revista de Ciências Jurídicas, 17(1), 11-17. 


\title{
Application of the PDCA cycle and quality tools in reducing costs and losses in a hortifruti distributor
}

\begin{abstract}
Product returns upon delivery to the customer are largely responsible for rework and reprocessing, increasing company costs and compromising the quality of the final product. This work aims to classify and quantify the reasons for returns, search for causes, propose solutions and improvements through the application of the PDCA cycle and quality tools, such as: "Flowchart", "Verification Sheet", "Brainstorming", "Pareto Chart", "Ishikawa Diagram" and " 5 W2H". The most frequent reason identified was returns for quality (49.9\%), followed by commercial agreement (20.8\%) and excess merchandise (11.9\%). The main causes of quality returns are due to the receipt of low quality raw materials and the lack of product shipping inspections.
\end{abstract}

Keywords: Quality Tools; Returns; Vegetables.

\section{Sobre os Autores}

\section{Rosane Sales de SOUSA}

Especialista em Engenharia de Produção. Centro Universitário Farias Brito, Rua Barão do Rio Branco, 2424, Centro, Fortaleza, CE, Brasil, CEP 60025-060.

E-mail: rosanesales7@gmail.com

\section{Maurício Johnny LOOS}

Pós-Doutor em Gestão Industrial. Professor do Centro Universitário Farias Brito, Rua Barão do Rio Branco, 2424, Centro, Fortaleza, CE, Brasil, CEP 60025-060.

E-mail: mauricioloos@hotmail.com 